\title{
Uno
}

\section{Ética y privacidad: De la filosofía \\ teórica a la \\ aplicación práctica}

DOI: 10.29236/sistemas.n153a6

"Había que vivir -y en esto el hábito se convertía en un instinto- con la seguridad de que cualquier sonido emitido por uno mismo sería registrado y escuchado por alguien y que, excepto en la oscuridad, todos los movimientos serían observados". George Orwell, 1984

\section{Resumen}

La ética aplicada, no como un concepto etéreo, a los derechos de privacidad e intimidad, es una necesidad real. Ante los avances tecnológicos, retomar el estudio ético y la importancia de la privacidad e intimidad como derechos humanos fundamentales resulta necesario para analizar el actuar desde distintas perspectivas. Volver a encontrarles significado a estos conceptos y explicar el motivo por el cual no han perdido vigencia, sino que incluso son más importantes que nunca, implica tomar conciencia no sólo de los aspectos jurídicos que conllevan, sino también de la praxis ética.

\section{Palabras claves}

Privacidad, ética, protección de datos, intimidad. 


\section{Introducción}

Vivimos una época en que la privacidad e intimidad parecen derechos olvidados o de un pasado muy lejano, en donde a cambio de un servicio digital no nos cuestionamos qué información entregamos y el uso que le darán a estos datos. Desde la perspectiva filosófica, el concepto de ética se ha visto como un aspecto casi metafísico, que solamente preocupaba a los antiguos griegos, o un aspecto meramente académico que los más recientes filósofos enseñan en las universidades. Sin embargo, el análisis ético de la cibersociedad en que vivimos, donde debemos cuestionarnos nuestro actuar profesional, empresarial y personal frente a la privacidad, parece más necesario que nunca; generar una ética aplicada y un derecho a la privacidad e intimidad renovado debe estar más presente que nunca, a pesar de que muchas veces no lo visualicemos.

\section{De la ética teórica a una ética aplicada}

Comprender el concepto de ética nos retorna a aspectos de base filosófica, en el marco de la praxis y se debe establecer una concepción de ética aplicada. Es común escuchar en los estudiantes universitarios la pregunta ¿para qué sirve la ética?, y esa pregunta debe ser el norte en el que busquemos una respuesta, un ámbito en que la filosofía sea práctica.
La ética ha sido delimitada conceptualmente como "aquella parte de la filosofía que se dedica a reflexionar sobre lo moral, un saber que busca construirse racionalmente, que le permita entender la dimensión moral de las personas" (Cortina \& Martínez, 2015, p. 09). Es decir, nos enfrentamos a buscar las respuestas de tres preguntas que generan actividades prácticas (Rodríguez, 2011, p. 23):

¿En qué consiste el fenómeno de lo moral?

¿Cómo debemos vivir los seres humanos?

¿Por qué debemos vivir los seres humanos de la manera que nos señala la ética?

Los saberes prácticos de la ética, que van de la mano con los saberes normativos como reglas del reflejo ético de una sociedad, buscan orientarnos sobre "qué debemos hacer para conducir nuestra vida de un modo bueno y justo, cómo debemos actuar, qué decisión es la más correcta en cada caso concreto para que la propia vida sea buena en su conjunto" (Cortina y Martínez, 2015, p. 11). La ética nos hace preguntarnos ¿por qué debemos tenerla en cuenta?, ¿qué argumentos avalan y sostienen el código moral que estamos aceptando como guía de conducta?, entendiendo moral como ese conjunto de 
principios, normas y valores que cada generación transmite a la siguiente en la confianza de que se trata de un buen legado de orientaciones sobre el modo de comportarse para llevar una vida buena y justa.

La ética y su análisis de la moral trasciende a poder aplicar sus descubrimientos a los distintos ámbitos de la vida, incluida, como analizaremos más adelante, la privacidad; como señalan Cortina y Martínez (2015), "no es hacer una aplicación mecánica de los principios éticos a los distintos campos de acción, sino que es menester averiguar cuáles son los bienes internos que cada una de esas actividades debe aportar a la sociedad y qué valores y hábitos es preciso incorporar para alcanzarlos" (Cortina y Martinez, 2015, p. 151).

Este proceso no puede ser en solitario, es un trabajo cooperativo, con expertos en cada área, una verdadera acción interdisciplinaria. Al respecto, Cortina y Martínez (2015) señalan que el planteamiento de la ética aplicada tiene que aclarar cuál es su método propio (cómo se relaciona el plano de los principios éticos y el de las acciones concretas), cuál es el marco de valores cívicos que debe tener en cuenta y los valores propios de cada actividad (Cortina y Martinez, 2015, p. 152). Por esta razón, cada actividad tendrá su propia base ética aplicada dependiendo de la actividad que se desarrolle.
Ahora bien, ¿cómo llevamos un modelo ético a la práctica? Cortina y Martínez (2015) realizan una propuesta que resulta bastante efectiva para distintos campos, incluida la privacidad; se trata de generar una hermenéutica crítica, la cual busca descubrir en los distintos ámbitos la "peculiar modulación del principio común" (p. 159), teniendo en consideración la especificidad de cada campo de estudio.

Ahí reside la necesidad de una interdisciplinariedad, toda vez que los especialistas de cada campo permitirán "determinar qué principios de alcance medio y qué valores se perfilan en él y cómo deben aplicarse dichos principios y valores en los diferentes contextos" (Cortina \& Martínez, 2015, p. 159).

Es importante señalar que la ética aplicada refleja la insuficiencia de la ética individual, en razón a que la voluntad personal puede producir consecuencias para la colectividad. Como señalan Cortina y Martínez (2015), "es necesario transitar de la lógica de la acción individual a la de la acción colectiva, recordando que es necesario contar con instituciones, pero que estas instituciones se tratan de actividades sociales" (Cortina y Martinez, 2015, p. 160).

Cortina y Martínez (2015, p. 165) brindan seis puntos de referencia para una articulación de una ética aplicada de cada actividad, a saber: 
1) Determinar claramente el fin específico, el bien interno por el que cobra su sentido y legitimidad social.

2) Averiguar cuáles son los medios adecuados para producir ese bien en una sociedad moderna.

3) Indagar qué virtudes y valores es preciso incorporar para alcanzar el bien interno.

4) Descubrir cuáles son los valores de la moral cívica de la sociedad en la que se inscribe y qué derechos reconoce esa sociedad a las personas.

5) Averiguar qué valores de justicia exige realizar en ese ámbito el principio de la ética del discurso, propio de una moral crítica universal, que permite poner en cuestión normas vigentes.

6) Dejar las tomas de decisión en manos de los afectados los cuales, con la ayuda de instrumentos de asesoría, ponderarán las consecuencias sirviéndose de criterios tomados de distintas tradiciones éticas.

Acompañada de estos seis puntos de referencia, la toma de decisiones debe ir conducida de lo que denominan la actividad de la que se ocupan y la meta por la que esa actividad cobra sentido; los valores, principios y actitudes que hay que desarrollar para alcanzar la propia meta.

\section{Privacidad e intimidad}

Ahora bien, cuando hablamos de derecho a la intimidad lo relacionamos con conceptos como privacidad, secreto, inviolabilidad y anonimato, todos estos como parte del mismo derecho.

Podemos definirlo entonces como "un derecho humano fundamental por virtud del cual se tiene la facultad de excluir o negar a las demás personas del conocimiento de ciertos aspectos de la vida de cada persona que solo a ésta le incumben" (De Dienheim, s.f., p. 01).

Este derecho va a implicar dos momentos, uno activo y uno pasivo (Rojas, 2008, p. 17), los cuales los podemos definir como:

- La posibilidad que tiene cada persona de excluir ciertos aspectos de su vida del conocimiento e intervención de terceras personas.

- La obligación de terceras personas de respetar la esfera de privacidad y no actuar contra esta.

Asimismo, es importante recordar que los Estados respetuosos de los derechos humanos se encuentran en la obligación de asegurar a las personas ese derecho a la intimidad, según su Constitución Política, lo que obliga directamente a velar por la privacidad de los ciudadanos, pero, al mismo tiempo, a brindar instrumentos capaces de restituir la privacidad cuando haya 
sido violada, y los medios legales para sancionar a los que la afecten.

En este aspecto, es importante recordar que actualmente las comunicaciones no solo deben ser entendidas como la transmisión de datos por algún medio tecnológico, sino que incluyen la comunicación escrita o digital, y estas tienen la característica de ser consideradas de índole privada.

Por esta razón, los marcos normativos de los diferentes Estados donde exista el respeto a los derechos humanos van a exigir que, en caso de alguna revisión de las comunicaciones de cualquier tipo o de la información contenida en dispositivos digitales, deba existir un debido proceso y mantener las garantías de intimidad de los elementos de índole privada. Dentro de los marcos normativos de referencia internacional tenemos la Declaración Universidad de los Derechos Humanos (Organización de Naciones Unidas, 1948), la cual en su artículo 12 establece que nadie será objeto de injerencias arbitrarias en su vida privada, su familia, su domicilio o su correspondencia, ni de ataques a su honra o a su reputación y que toda persona tiene derecho a la protección de la ley contra esas injerencias o ataques; el Pacto Internacional de Derechos Civiles y Políticos (Asamblea Legislativa, 1968), el cual en su artículo 17 establece las mismas disposiciones que el artículo 12 de la Declaración Universal de los Derechos Huma- nos y en su artículo 19, al referirse a la libertad de expresión, señala que esta genera deberes y responsabilidades especiales, por lo que podrá estar sujeta a ciertas restricciones fijadas por la ley y que sean necesarias para asegurar el respeto a los derechos o a la reputación de los demás, así como para proteger la seguridad nacional, el orden público, la salud o moral públicas.

La Convención Americana sobre Derechos Humanos (Asamblea Legislativa, 1970) estableció, en el artículo 11, que toda persona tiene derecho al respeto de su honra y al reconocimiento de su dignidad y que, por tanto, no deberá ser objeto de injerencias arbitrarias o abusivas en su vida privada, familia, domicilio, correspondencia, ni deberá sufrir ataques ilegales a su honra o reputación. Además, establece el derecho de la persona a ser protegida por la ley contra esas injerencias o ataques.

El artículo 13 establece la libertad de pensamiento y expresión determinando que no deberá existir previa censura, pero que el ejercicio de esos derechos estará sujeto a responsabilidades ulteriores, las cuales deberán estar expresamente fijadas por la ley y deberán tender a asegurar, entre otras cuestiones, el respeto a los derechos o a la reputación de los demás. La Convención sobre los Derechos del Niño (Asamblea Legislativa, 1990), en su artículo 16, menciona que ningún niño será objeto de injerencias 
arbitrarias o ilegales en su vida privada, su familia, su domicilio o su correspondencia, ni de ataques ilegales a su honra o a su reputación, y que el niño tiene derecho también a la protección de la ley contra esas injerencias y ataques.

De igual forma, muchos de los países han integrado dentro de sus marcos normativos responsabilidad en materia de privacidad digital y leyes de protección de datos. Estas buscan generar un impacto aplicado en el mundo tecnológico sobre la protección de los datos desde una perspectiva ciudadana de poder ejercer derechos frente a las empresas e instituciones, además de crear agencias de protección de datos con herramientas jurídicas con las que puedan, o intenten, ejercer acciones contra el mal manejo de la información, incluidas fugas de información u otras acciones que afecten la privacidad.

Existe normativa en materia laboral que busca que los trabajadores no divulguen información, digital o impresa, además de las responsabilidades dentro del ámbito laboral que implican la pérdida de confianza. Por ejemplo, en la legislación laboral costarricense se encuentran los artículos 71 y 81 , los cuales detallan lo siguiente:

\section{Artículo 71.}

Fuera de las contenidas en otros artículos de este Código, en sus Reglamentos y en sus leyes suple- torias o conexas, son obligaciones de los trabajadores:

(...)

Guardar rigurosamente los secretos técnicos, comerciales o de fabricación de los productos a cuya elaboración concurran directa o indirectamente, o de los cuales tenga conocimiento por razón del trabajo que ejecutan; así como de los asuntos administrativos reservados, cuya divulgación pueda causar perjuicios al patrono

\section{Artículo 81.}

Son causas justas que facultan a patrono para dar por terminado el contrato de trabajo:

\section{$(\ldots)$}

Cuando el trabajador revele los secretos a que alude el inciso g) del artículo 71;

Asimismo, en materia penal se han creado tipos penales que responsabilizan a las personas por violentar la privacidad; por ejemplo, violación de datos personales, violación de comunicaciones, entre otros. No obstante, tener estos marcos normativos no parece ser suficiente para no afectar la privacidad e intimidad. No es renunciar a las respuestas jurídicas, pero debemos buscar otras vías que permitan hacer efectiva la protección de la privacidad sin tener que recurrir, si es que es posible, a la disuasión legal 
de ser castigado por una acción desde una perspectiva de una ética deontológica.

\section{Reflexiones finales}

Estamos en una época donde no se cuestiona el motivo de usar nuestros datos mientras nos ofrezcan cualquier servicio digital; la normativa no protege a ese ciudadano desinformado que realiza un "trueque" de su privacidad. Por lo tanto, uno de los principales ejes a trabajar es el poder generar una cultura digital y un ciudadano consciente de la importancia de sus datos.

Del otro lado de la moneda están los que por sus funciones trabajan con los datos personales, sean técnicos o no, y que muchas veces no han considerado la importancia y lo delicado de su labor. Este proceso también requiere de cultura digital, esta formación debe ir enmarcada en la aplicación de los seis puntos de referencia para una articulación de la ética aplicada comentada anteriormente. Los profesionales en tecnología no pueden sólo contar con una buena habilidad técnica y ser socialmente diestros; es cierto que las normas absolutas ya no las tenemos, pero, como señalan Cortina y Martínez (2015), "solo una educación moral que propicie el diálogo abierto entre las personas consideradas como interlocutores válidos puede dar lugar al desarrollo de ellas mismas como personas críticas y responsables" (Cortina y Martinez, 2015, p. 183).
Debemos plantear incluir el tema de privacidad y ética en la educación general básica o en los cursos a nivel universitario, no sólo como pequeñas pinceladas, sino que debe ser un tema transversal a lo largo de todo el proceso de formación ciudadana. La ética nos permite, de manera razonada y aplicada, pasar de un aspecto teórico a uno práctico. Desde la perspectiva teórica, debemos tener presente el carácter normativo, esos principios generales basados en la argumentación y la reflexión filosóficas para el análisis de la conducta moral y poder llevar a la praxis el decidir la solución frente a un problema moral específico aplicado a la vida diaria. La ética teórica es la que nos brindará esas herramientas que permiten llevar esa solución a los problemas morales prácticos de la vida diaria; por esto, de cara a los retos de nuestro actuar frente a la privacidad, debemos volver los ojos al análisis ético para no solamente ser usuarios pasivos frente a lo que sucede con nuestros datos, sino personas críticas y reflexivas que hagan valer sus derechos de privacidad, que les den la importancia a sus datos y, si les corresponde administrarlos, que lo hagan de una manera ética y responsable.

\section{Referencias}

Asamblea Legislativa. (11 de diciembre de 1968). Pacto Internacional de Derechos Civiles y Políticos.

Recuperado de:

http://www.pgrweb.go.cr/scij/Busqued a/Normativa/Normas/nrm_norma.aspx 
?param1 $=$ NRM \&nValor $1=1 \&$ nValor $2=$ 20579\&nValor3=0\&strTipM=FN

Asamblea Legislativa. (23 de febrero de 1970). Convención Americana sobre Derechos Humanos (Pacto de San José). Recuperado de:

http://www.pgrweb.go.cr/scij/Busqued a/Normativa/Normas/nrm_norma.aspx ?param1=NRM\&nValor1=1\&nValor2= 36150\&nValor3=38111\&strTipM=FN

Asamblea Legislativa. (09 de agosto de 1990). Convención sobre los Derechos del Niño.

Recuperado de:

http://www.pgrweb.go.cr/scij/Busqued a/Normativa/Normas/nrm_texto_comp leto.aspx?param1=NRTC\&nValor1=1 \&nValor2=6606\&nValor3=7032\&strTip $\mathrm{M}=\mathrm{TC}$

Cortina, A., y Martínez, E. (2015). Ética. Akal.

De Dienheim, C. (s.f.). El derecho a la intimidad, al honor y a la propia imagen. Recuperado de:

http://www.unla.mx/iusunla3/reflexion/ derecho\%20a\%20la\%20intimidad.htm

Organización de Naciones Unidas. (10 de diciembre de 1948). Declaración Universal de Derechos Humanos. Recuperado de: http://www.pgrweb.go.cr/scij/Busqued a/Normativa/Normas/nrm_texto_comp leto.aspx?param $1=$ NRTC\& $n$ Valor $1=1$ \&nValor2 $=49015 \&$ nValor3 $=52323 \&$ str TipM=TC

Rodríguez, G. (2011). Ética ¿para qué? Pearson Education, México.

Rojas, G. E. (08 de mayo de 2008). Secreto en las comunicaciones electrónicas: medios para lograr prueba válida en un proceso penal. Recuperado de: http://iij.ucr.ac.cr/wpcontent/uploads/bsk-pdfmanager/2017/07/Secreto-en-lascomunicaciones-electronicas.pdf

Roberto Lemaître Picado. Egresado de la Maestría Profesional en Computación e Informática de la Universidad de Costa Rica, Licenciado en Derecho por la Universidad de Costa Rica, Ingeniero Informático por la Universidad Estatal a Distancia y Técnico en Computación por el Colegio Vocacional Monseñor Sanabria. Profesor en la Universidad de Costa Rica y de la Universidad Técnica Nacional. Especialista en delitos informáticos, protección de datos, Derecho y tecnología. 